\title{
Capturing Waste Heat Energy with Charge-Transfer Organic Thermoelectrics
}

\author{
Vladimir Dimitrov,* Simon Woodward* \\ Laboratory of Organic Synthesis and Stereochemistry, Institute of Organic Chemistry with Centre of \\ Phytochemistry, Bulgarian Academy of Sciences, Acad. G. Bonchev, Build. 9, Sofia 1113, Bulgaria \\ vdim@orgchm.bas.bg
}

GSK Carbon Neutral Laboratories for Sustainable Chemistry, Jubilee Campus, University of Nottingham, Nottingham NG7 2TU, United Kingdom

simon.woodward@nottingham.ac.uk

\begin{abstract}
Electrically conducting organic salts, known for over 60 years, have recently demonstrated new abilities to convert waste heat directly into electrical power via the thermoelectric effect. Multiple opportunities are emerging for new structure-property relationships and new materials to be attained through synthetic organic chemistry. This review highlights key aspects of this field, which is complimentary to current efforts based on polymeric, nanostructured or inorganic thermoelectric materials and indicates opportunities whereby main stream organic chemists can contribute.

$1 \quad$ What are thermoelectrics? And why use them?

2 Current organic and hybrid thermoelectrics

3 Unique materials from tetrathiotetracenes

$4 \quad$ Synthesis of tetrathiotetracenes

$5 \quad$ Materials and device applications

$6 \quad$ Future perspective
\end{abstract}

Key words organic materials, synthesis, synthetic metals, organic thermoelectrics, acenes

\section{What are thermoelectrics? And why use them?}

Seebeck (in 1821-2) noted that suitably combined $\mathrm{p}$ and $\mathrm{n}$ thermoelectric (TE) materials generate a voltage $(\alpha)$ when placed between two temperatures: $T_{\text {hot }}$ and $T_{\text {cold. }}{ }^{1}$ Maximising the electrical voltage, current and hence power, induced down the temperature gradient requires electrical carrier transport (via holes or electrons) to outperform heat energy transport (via lattice vibrations). The theoretical maximum (Carnot) efficiency $\left(\eta_{\max }\right)$ of any TE device, all potentially capable of converting waste heat into electrical power, is $\eta_{\max }=\left(1-\mathrm{T}_{\text {cold }} / \mathrm{T}_{\text {hot }}\right)$. For lower temperature operation e.g. $\mathrm{T}_{\text {hot }}=200$ to $\mathrm{T}_{\text {cold }}=25{ }^{\circ} \mathrm{C}$ (the temperatures where most global waste heat abounds) this corresponds to $\eta_{\max }=35 \%$ theoretically (and typically $<8 \%$ in real devices). Using TE materials for waste heat energy extraction is complicated by the fact that thermal ( $\kappa)$ and electrical $(\sigma)$ conductivity often scale linearly with each other (the Wiedemann-Franz law). The effectiveness of any TE material, at temperature T, is thus usually defined by the dimensionless comparator $\mathrm{ZT}$ where ZT $=\sigma \alpha^{2} / \kappa$. For efficient energy harvesting applications ZT values $>1$ are needed at the temperature of operation (T). Simultaneous high electrical and low thermal conductivity are needed to access such performance. Common thermoelectric materials (Figure 1) often underperform (ZT $=0.01-0.25$ is not atypical) at lower temperatures, and the few that are effective at $200 \rightarrow 25^{\circ} \mathrm{C}$, like $\mathrm{Bi}_{2} \mathrm{Te}_{3},{ }^{1,2}$ have poor sustainability (tellurium is rarer than gold!). Electrically conducting organic TE materials ${ }^{3}$ (Figure 1) potentially could fill this niche offering lower cost, sustainable, waste energy recovery. Saving $8 \%$ of the current global heat energy wasted below $200{ }^{\circ} \mathrm{C}$ would amount to $\sim 325 \mathrm{TW} . \mathrm{h}$ - greater than the annual electrical energy consumption of most European countries. As an added advantage run in inverse operation highly efficient TE devices allow motionless refrigeration options via the Peltier effect. ${ }^{1}$ 


\begin{tabular}{|c|c|c|c|c|c|}
\hline & Example & $\begin{array}{c}\sigma \\
\left(\mathrm{S} \mathrm{cm}^{-1}\right)\end{array}$ & $\begin{array}{c}\alpha \\
\left(\mu \vee K^{-1}\right)\end{array}$ & $\begin{array}{c}\kappa \\
W m^{-1} K^{-}\end{array}$ & (at $298 \mathrm{~K}$ ) \\
\hline \multirow{2}{*}{$\begin{array}{c}\text { Unsuitable } \\
\text { poor materials }\end{array}$} & Aluminium & $\sim 10^{5}$ & -1.8 & 205 & 0.0002 \\
\hline & p-type silicon & 75 & +200 & 148 & 0.0006 \\
\hline $\begin{array}{l}\text { Unsustainable } \\
\text { inorganic TE }\end{array}$ & p-type $\mathrm{Bi}_{2} \mathrm{Te}_{3}$ & 900 & +215 & 1.5 & 0.83 \\
\hline $\begin{array}{l}\text { Desired organic } \\
\text { TE materials }\end{array}$ & $\begin{array}{c}\text { Ideal } \\
\text { Organic TE }\end{array}$ & $\geq 10^{3}$ & $\stackrel{+}{\text { or }} \geq 120$ & $\leq 0.4$ & 1.0 \\
\hline
\end{tabular}

Figure 1. From unsuitable to ideal materials for low temperature waste heat recovery and some parameters to compare their performance by. The Power Factor $\left(\mathrm{PF}=\sigma \alpha^{2}\right)$ of an ideal organic TE material would be $\geq 1440 \mu \mathrm{W} \mathrm{m}{ }^{-1} \mathrm{~K}^{-2}$, comparing favourably with that of doped $\mathrm{Bi}_{2} \mathrm{Te}_{3}\left(\mathrm{PF}=4160 \mu \mathrm{W} \mathrm{m} \mathrm{K}^{-1} \mathrm{~K}^{-2}\right.$. These power factor values were calculated from the $\sigma$ and $\alpha$ values within the Figure.

\section{Current organic and hybrid thermoelectrics}

Organic materials were realised to possess thermoelectric properties from the early 1970s within the fields of organic semiconductors and conducting polymers. In general, organic TE materials offer rather low thermal conductivity $(\kappa)$, significant Seebeck coefficients $(\alpha)$ and tuneable, but often low, electrical conductivity $(\sigma)$. As $\sigma=\mathrm{qn} \mu$ [where $\mathrm{q}$ is the charge on an electron (or hole), $\mathrm{n}$ the free carrier density and $\mu$ the charge carrier mobility], known organic (semi-)conductors showing values of $\mathrm{n}$ and $\mu$ of $10^{10}$ to $10^{16} \mathrm{~cm}^{-3}$ and $10^{-4}$ to $\sim 10$ $\mathrm{cm}^{2} \mathrm{~V}^{-1} \mathrm{~s}^{-1}$ respectively can be theoretically doped into providing $\sigma$ in the range $10^{-5}-10^{6} \mathrm{~S} \mathrm{~cm}^{-1}$. Rich synthetic methods exist for the synthesis of structurally varied organic (semi-)conductors, ${ }^{4}$ offering opportunities for increasing $\sigma$ while maintaining or degrading $\kappa$. Caution should be exercised though due to the mutual interdependence of $\sigma$ and $\kappa$ in classical conductors. Low temperature waste energy harvesting organic TEs are considered promising due to the potential for new materials discovery via easily prepared libraries, coupled with effective scale-up, reasonable price and very suitable solution based processes for purification and utilization in devices. Research activity in organic TE materials has grown rapidly (Figure 2) but the majority of this interest has somewhat remained within the materials (especially polymer) communities and large future potential opportunities for the involvement of mainstream synthetic organic chemists exists.

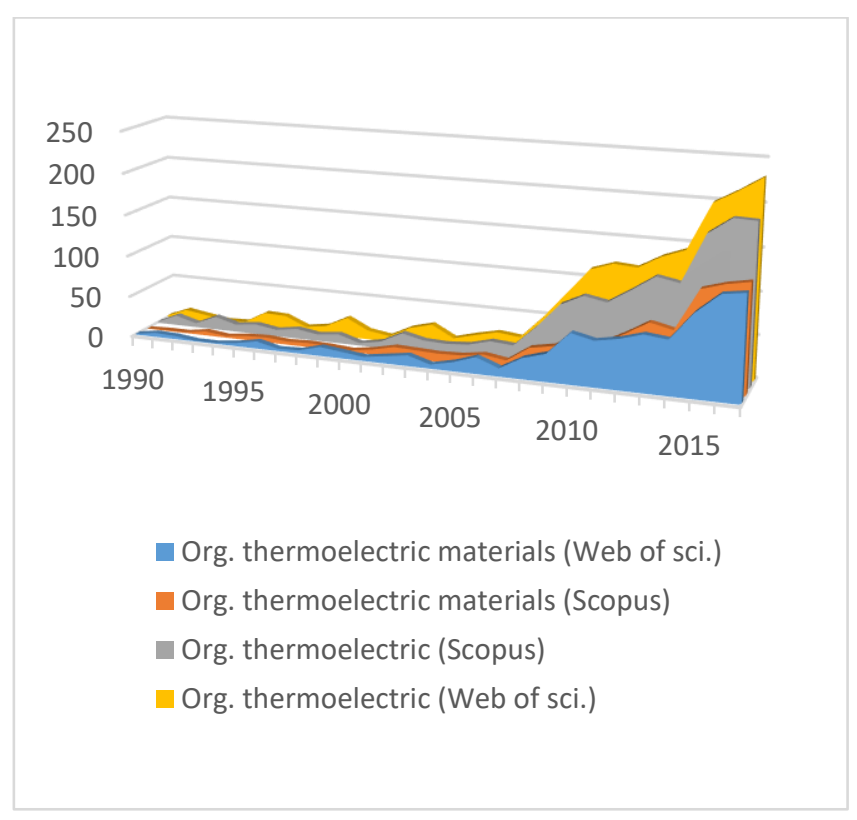

Figure 2. Number of publications covering the terms "organic thermoelectric materials" and "organic thermoelectric" from 1990 up to the end of 2017 (according Scopus and Thomson Reuters Web of Science). 
Measuring thermal conductivity $(\kappa)$ values can sometimes be challenging and in its absence the Power Factor $\left(\mathrm{PF}=\sigma \alpha^{2}\right)$ of a material is a useful alternative comparator. From a chemical point of view current organic and hybrid TEs can be roughly divided into three classes, ${ }^{3}$ leading exemplars of which are shown in Scheme 1:

- Conducting polymers - including purely organic systems such as polyaniline (PANI) and poly $(3,4-$ ethylenedioxythiophene) (PEDOT) together with metallo-coordination-polymers such as poly(nickel 1,1,2,2-ethenetetrathiolates).

- Nanocomposite materials - typically combinations single or double wall carbon nanotubes (or other carbon allotropes) with conducting polymers or other diverse promoters. By using a multi-layering approach very high power factors have been attained, but empirical optimisation has plays a major role in such studies.

- Small molecules - Appropriately electron-rich (or poor) molecules with diffuse electron density are known to exhibit significant Seebeck values. For example, pentacene films show $\alpha \sim 250 \mu \mathrm{V} \mathrm{K}{ }^{-1}$ which under appropriate doping afford moderately efficient organic thermoelectric p-type phases. Such strategies are subject to the proviso that the required oxidation or reduction (charge transfer) products are stable.

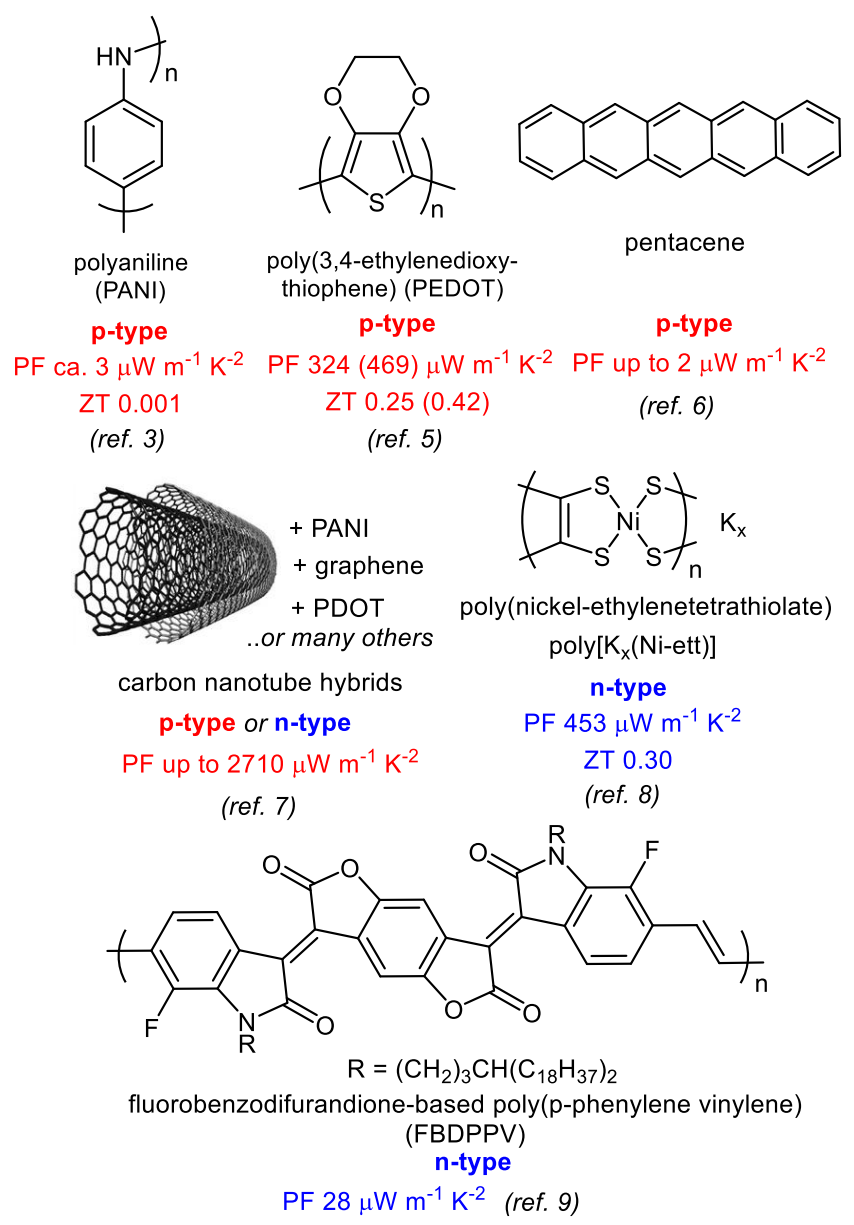

Scheme 1. Current exemplary leading materials in organic and hybrid TE discovery. Exceptional materials are still a rarity; the majority of the organic TEs thus far investigated show $\mathrm{PF}<5 \mu \mathrm{W} \mathrm{m} \mathrm{K}^{-1} \mathrm{~K}^{-2}$ and ambient ZT values $<10^{-2}$. Two values for the ZT of PEDOT materials are given: 0.25 has been established by many groups, but ZT values of 0.42 and higher have been the subject of some debate.

While representative of the current organic TE area, the compounds of Scheme 1 are only a small fraction of those that have been trialled in TE studies. In all cases appropriate doping (addition or removal of electrons 
to the basic TE materials is required to increase $\sigma$. However, $\alpha$ is typically found to fall as $\sigma$ increases and careful optimisation of the doping levels is required in maximising PF and ZT. By such stratergies remarkable progress has been made towards attaining viable organic TE technology but many issues remain to be resolved. For example, while Grunlan's hybrid carbon nanotube materials (Scheme 1) deliver performance comparable to commercial $\mathrm{Bi}_{2} \mathrm{Te}_{3}$ they require the deposition of more than 300 separate layers! Intrinsic constraints may also to exist. Recent data mining revealed that most organic TEs show interdependence of the electrical conductivity and Seebeck coefficient, such that $\alpha \propto \sigma^{-1 / 4}$ leading to PF $\propto$ $\sigma^{-1 / 2} \cdot{ }^{10}$ These relationships suggest that (re)investigating 'synthetic metals' [organic phases showing exceptionally high electrical conductivities $(\sigma)$ similar to metals, with significant Seebeck coefficients] could offer an alternative non-polymer route to high performance organic TE materials.

\section{Unique materials from tetrathiotetracenes (450-700 words, currently 671)}

Bechgaard and Jerome's seminal 1979 observation ${ }^{11}$ of superconductivity in the organic salt (TMTSF)(PF $)_{2}$ precipitated a global (but ultimately unsuccessful) quest for related organic materials that could remain superconducting above more than a few Kelvin. Tetrathiotetracene ( $\mathbf{1}$ in Figure 3, commonly referred as TTT, but also called naphthaceno[5,6-cd:11,12-c'd']bis[1,2]dithiole or tetrathionaphthacene; CAS Registry Number [193-44-2]) is a deep black-green material that became a pre-eminent candidate in this period due to the ease with which can form highly conducting (almost metallic) charge transfer complexes upon oxidation. ${ }^{12}$ TTT 1 has a justifiable reputation as being a highly insoluble species $\left(<10^{-4} \mathrm{M}\right.$ in most organic solvents), that is hard to work with, and hard to attain in high purity as demonstrated by its wide reported melting point $\left(337-410^{\circ} \mathrm{C}\right.$ ). It is best sublimed at $10^{-6} \mathrm{mbar}$ (with $\mathrm{T}_{\text {sub }} \sim 225^{\circ} \mathrm{C}$ ), as use of more aggressive conditions $\left(>270^{\circ} \mathrm{C}\right.$ at $10^{-1} \mathrm{mbar}$ ) leads sulfur redistribution reactions and decomposition. Bulk TTT 1 is somewhat air sensitive, although stable for at least days under aerobic conditions, it is easily oxidised by agents more potent than $\mathrm{O}_{2}$. Its electrical conductivity can be used to estimate oxidative degradation ranging from $\sim 10^{-4} \mathrm{~S} \mathrm{~cm}^{-1}$ for impure (aerobic oxidised samples) to $10^{-5}$ to $10^{-6} \mathrm{~S} \mathrm{~cm}^{-1}$ for pristine vacuum sublimed TTT (1). Deliberate oxidation of TTT 1 leads to stable (p-type) charge transfer complexes of approximate stoichiometries [TTT]X or [(TTT $\left.)_{2}\right] \mathrm{X}$ where $\mathrm{X}$ is a mononuclear or polynuclear anion, often based on iodine.
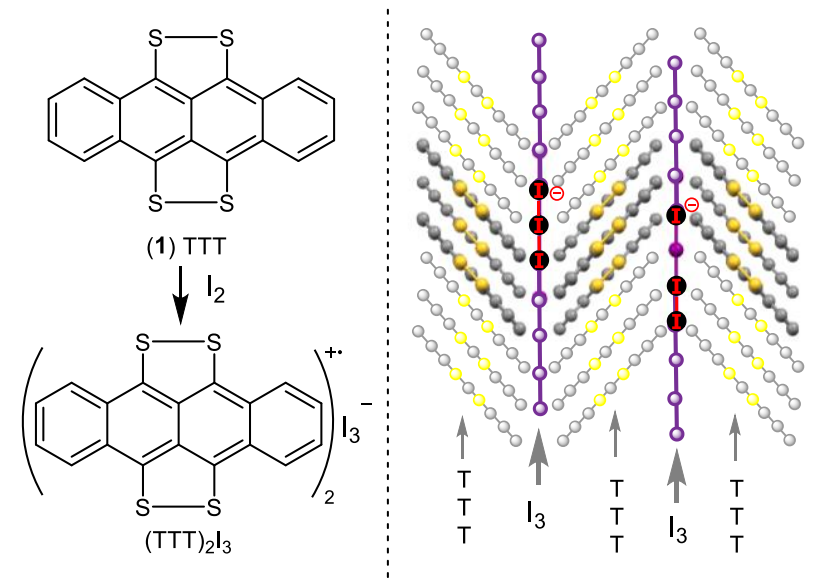

Figure 3. Formation of (TTT) $)_{2} I_{3+\delta}$ through reaction of $\mathbf{1}$ with $\mathrm{I}_{2}$ and its crystal packing diagram, viewed perpendicular to the $\mathrm{b}$-axis, showing the disordered $\mathrm{I}_{3}{ }^{-}$anion progressing down the needle length.

The latter can be isolated as lustrous golden needles of (TTT) $)_{2} \mathrm{I}_{3+\delta}(\delta \sim 0.1)$ (Figure 3) showing a high electrical conductivity of $\sigma \sim 10^{3} \mathrm{~S} \mathrm{~cm}^{-1}$ (about a tenth that of liquid mercury) down the needle length (which corresponds to the crystallographic b-axis, Figure 3).

Theoretically, the one dimensional electrical conductivity shown by (TTT) ${ }_{2} \mathrm{I}_{3+\delta}$ should be prevented by a Peierls transition to an insulating phase. ${ }^{14}$ However, disorder in the $I_{3}$ chains allows (TTT) ${ }_{2} I_{3+\delta}$ to achieve the 


\section{Short review for Synthesis}

simultaneous short and long-range (dis)order necessary for a 1D quasicrystal phase to be attained. ${ }^{15}$ This

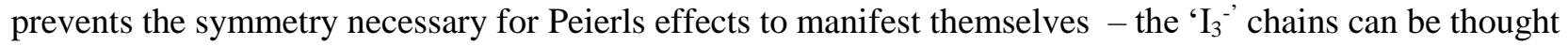
of as being composed of: $\mathrm{I}^{-}, \mathrm{I}_{2}$ and $\mathrm{I}_{3}{ }^{-}$leading to an absence of translational symmetry down the iodine-based counter anion chain. In (TTT) ${ }_{2} I_{3+\delta}$ two factors theoretically combine to facilitate the thermoelectric efficiency of the phase. Firstly, the quasi-one-dimensionality leads to an increase of the carrier density of states ${ }^{16}$ in (TTT $)_{2} \mathrm{I}_{3+\delta}$. Secondly, and most importantly in the case of $(\mathrm{TTT})_{2} \mathrm{I}_{3+\delta}$, there is partial compensation of two of the most important electron-phonon interactions for a narrow strip of states in the conduction band. This affects the relaxation time associated with charge transfer within (TTT) ${ }_{2} \mathrm{I}_{3+\delta}$ which becomes a sharp function of carrier energy leading to a sharp increase in the mobility of the charge carriers in these states. ${ }^{17}$ Provided the Fermi level of the (TTT) $)_{2} \mathbf{I}_{3+\delta}$ phase can be displaced (by optimization of the carrier concentration) towards this strip of states (those with increased mobility) dramatic increases in electrical conductivity and Seebeck coefficient are predicted. As the derived electrical conductivity grows faster than the electronic contribution to thermal conductivity the solid is predicted to show non Wiedemann-Franz type behaviour. ${ }^{18}$ The combination of these two factors suggest, theoretically, that (TTT) ${ }_{2} \mathrm{I}_{3+\delta}$ should be highly suited for thermoelectric applications. Unfortunately, these same theoretical studies also suggest that carrier scattering by impurities or defects and inter-chain vibrations will have significant negative effects on the observed electrical conduction and hence TE applicability. Similar preliminary studies ${ }^{13}$ indicate that $n$-type charge transfer complexes could be formed from mixtures of TTT and tetracyanoquinodimethane (TCNQ). However, prior to 2017 the preparative and purification issues associated with TTT (see above) severely limited experimental study of TE behaviour in these materials. Thus, in the next section it is appropriate to overview known classical and modern approaches to TTT molecules, and their tetracene precursors, applicable to eventual device preparation.

\section{Synthesis of tetrathiotetracenes}

The synthesis of TTT refers to a handful synthetic approaches, ${ }^{12}$ in which tetracene $(2, \mathrm{~T})$ is the core starting material. In some cases an alternatively suitably substituted tetracene derivative is used. Access to definitive synthetic procedural information in the primary literature is complicated. In some cases the initial reports are described only in patents or limited to early Soviet literature. ${ }^{19}$ An overview of known syntheses of unsubstituted and substituted TTT has recently been collected and this also demonstrates these literature accessibility issues. ${ }^{20}$ Evaluating the known experimental details, supplemented by our own experiences in this area, it is justified to suggest the direct reaction of tetracene $(2, \mathrm{~T})$, or one of its derivatives, with sulfur in refluxing DMF is the most appropriate way for the synthesis of TTTs. This path (A) was first outlined by Perez-Alberne (Scheme 2) as long ago as $1973 .{ }^{19 a}$ Typically, $>90 \%$ yields of crude products, containing only small amount of poly-sulfided material, are attained. For the synthetic approaches of pathways B, E and F there are insufficient data to estimate their efficiency and therefore they do not possess much practical importance at present. The synthesis of TTT (1) by using the substituted species in routes C, D, F and G is described to proceed in yields in the range $40-85 \% .{ }^{19 c-e}$ However, in these cases previous multistep synthetic approaches to the precursors are necessary in which the 6,11-dihydroxy-5,12-naphthacenedione (3, DND) is the key intermediate (the starting compound in path $\mathrm{C}$ is further used for the synthesis of all chlorosubstituted tetracenes). The cost of DND (3) ca. $20-100+€ / \mathrm{mmol}$ makes such manipulations viable on small scales but, but large scale preparation of (3) has not yet been widely taken up, even up even after significant process optimisation has appeared. ${ }^{21}$ Given the wider availability of various tetracenes (at similar cost) the method of choice, in our opinion, is pathway A which typically offers good yields and simple workups. ${ }^{20}$ For example, reaction of the parent tetracene $(2, \mathrm{~T})$ and elemental sulfur in DMF afford, after refluxing the mixture (4-5 h) and hot filtration, the desired TTT (1) in crude yields above 95\%. For purification, a simple Soxhlet extraction with toluene and/or $\mathrm{CS}_{2}$ is effective in removing sulfur impurities and a by-product identified a dithiotetracene. In this manner TTT (1) is produced in $>95 \%$ purity and good yield. To obtain TTT (1) for thermoelectric applications further purification by applying high vacuum sublimation is necessary. ${ }^{22}$ The most important properties of TTT have been demonstrated in Section 3 (above). 


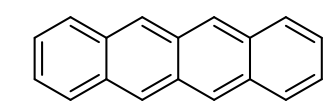

(2) $\mathrm{T}$<smiles>Clc1c2ccccc2c(Cl)c2c(Cl)c3ccccc3c(Cl)c12</smiles><smiles>Clc1c2ccccc2c(Cl)c2c(Cl)c3ccccc3c(Cl)c12</smiles>

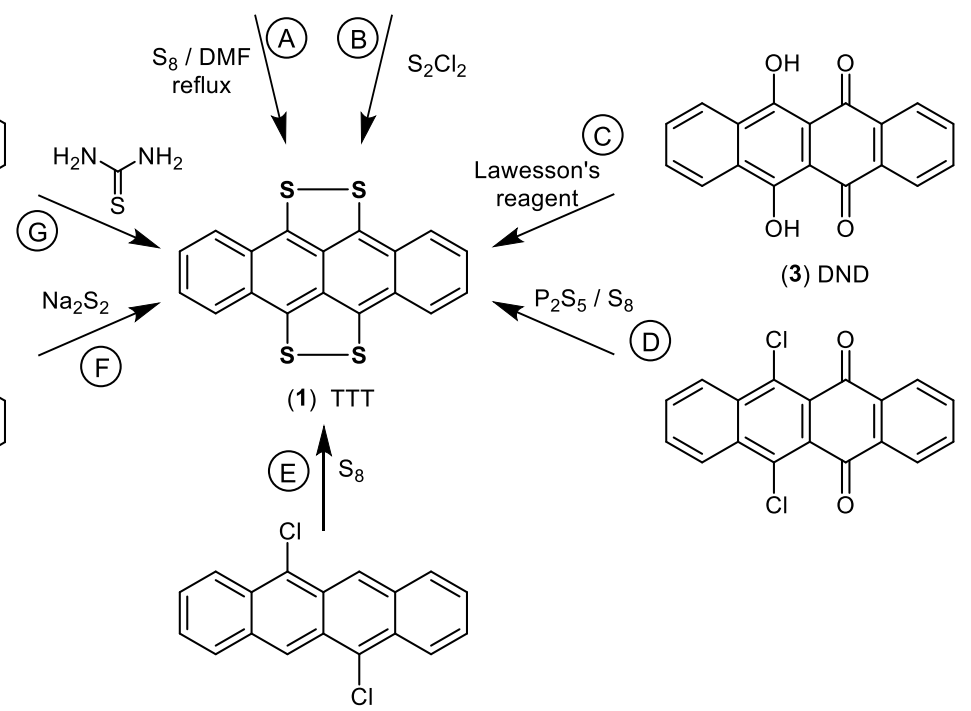

Scheme 2. Synthetic pathways for preparation of tetrathiotetracene (TTT, 1).

A key prerequisite in the production of TTT (1) is the availability of tetracene $(\mathbf{2}, \mathrm{T})$. As of 2018 we could identify eight providers of T (2) at prices between 22 to $140 € / \mathrm{mmol}$ (for quantities between $100 \mathrm{mg}$ to $5 \mathrm{~g}$ ). While custom synthesis of T (2) at larger scales is commonly offered very few (even simple) tetracene derivatives are commercially available. Practicable syntheses of T (2) and substituted derivatives ideally need to fulfil the following criteria for maximum utility: (i) minimised total step-count, (ii) use of only low cost sustainable starting materials, (iii) diversity orientated intermediates facilitating the preparation of substituted tetracene libraries, (iv) simple (chromatography-free) work-up procedures providing analytically pure intermediates and final tetracenes and (v) applicability to gram scales without yield or purity degradation issues. Synthetic approaches aspiring to these criteria and leading to generalised unsubstituted tetracenes are presented in Scheme 3. Some of these routes are also suitable for the synthesis of substituted tetracenes. In previous review articles different approaches for synthesis of tetracenes, and high acenes, have already been summarised. ${ }^{23}$ Therefore, here we present only the most practical synthetic approaches to producing tetracenes relevant for elaboration to TTTs.

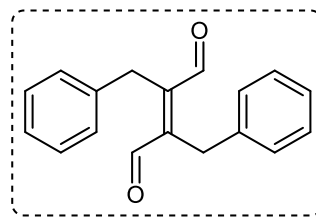<smiles>O=C1C=CC(=O)c2ccccc21</smiles>

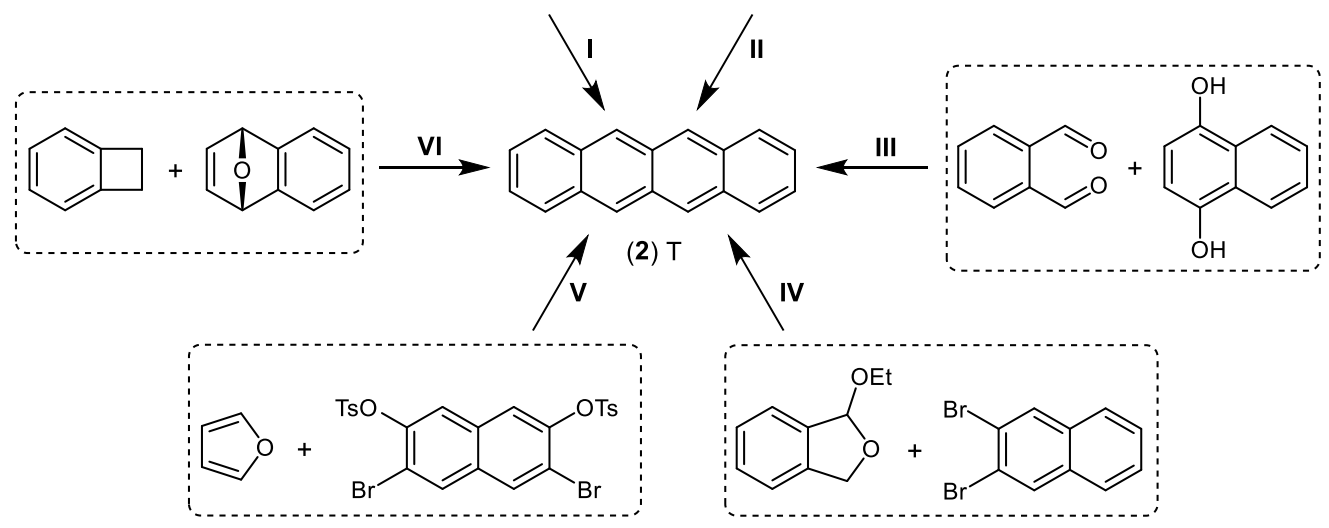

Scheme 3. Practical approaches for synthesis of tetracene (T, 2). 


\section{Short review for Synthesis}

Traditional routes to tetracene derivatives typically involve unidirectional synthesis from ortho substituted phenylene units wherein only one aryl ring is formed at a time (routes II-IV and VI) or in rare cases from diortho substituted naphthalenes allow bidirectional synthesis with two ring formation at a time (routes I and V). Potentially two directional approaches allow more rapid tetracene synthesis and this idea has been recently investigated (route I). ${ }^{24}$ This bidirectional synthesis of tetracenes calls for initial preparation of intermediates 4 and 5 (Scheme 4) by using: (i) copper catalysed direct addition of $\mathrm{ArCH}_{2} \mathrm{MgCl}$ to $\mathrm{HOCH}_{2} \mathrm{C} \equiv \mathrm{CCH}_{2} \mathrm{OH}$ leading to directed an $(E)$-carbomagnesiation intermediate which smoothly intercepts iodine providing compounds 4 (in 50-55\% yield) on $10 \mathrm{~g}$ scales for; or (ii) equally conveniently 5 directly precipitated as an off-white solid from simple reaction of 2-butyne-1,4-diol with iodine in $\mathrm{CHCl}_{3}$ on $>10 \mathrm{~g}$ scales ( $90 \%$ yield). ${ }^{24}$

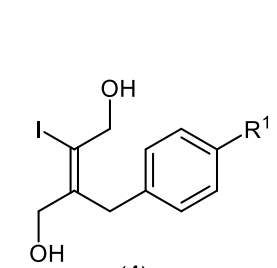

(4)

$\mathrm{R}^{1}=\mathrm{H}, \mathrm{Me}, \mathrm{OMe}$

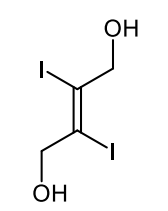

(5)
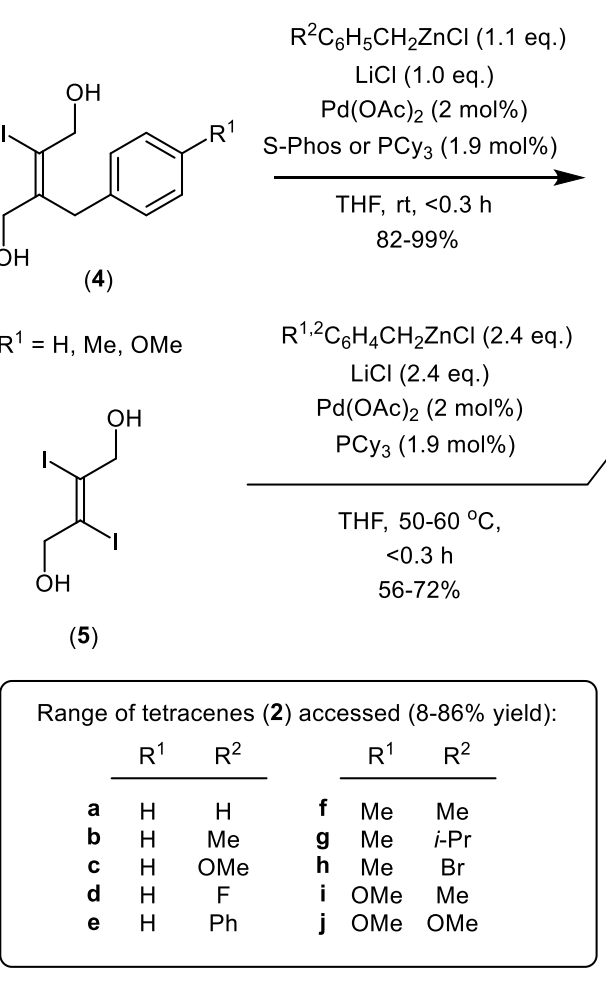

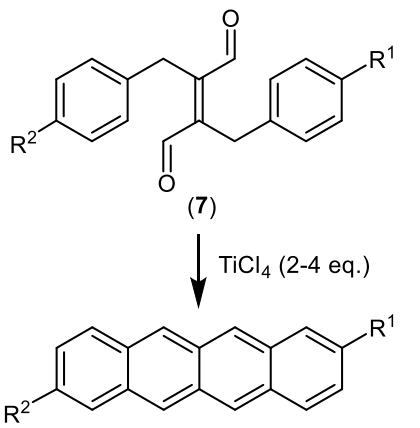

(2)

Scheme 4. Practical bidirectional synthesis of 2,8-substituted tetracenes (2). ${ }^{24}$

For the synthesis of the key diols 6 efficient Negishi-type couplings were developed followed by relatively simple purification. No protection of the free hydroxyl groups is required in these couplings as C-C coupling is faster than deprotonation events. Modified high yielding aerobic oxidation by $\mathrm{Cu}^{\mathrm{I}} / \mathrm{TEMPO}-$ based catalysis provides the aldehydes $\mathbf{7}$. The transformation of $\mathbf{7}$ to $\mathbf{2}$ occurs in poor to excellent yields depending on the substituents $R^{1}$ and $R^{2}$ and the Lewis acid applied. Normal $S_{E} A r$ behaviour is observed, if $R^{1} / R^{2}$ are electron releasing (e.g. alkyl, OMe, $\mathrm{Ph}$ ) high yields are realised (typically above $80 \%$ ). However, if $\mathrm{R}^{1} / \mathrm{R}^{2}$ is electron withdrawing only small amounts of tetracene (7) are produced (e.g. $\mathrm{R}^{1}=\mathrm{H}, \mathrm{R}^{2}=\mathrm{F}$ gives $\mathbf{2 d}$ in only $9 \%$ yield. The majority of the product, $37 \%$, being due to closure on just the electron-rich aryl group). The simplicity of the workup procedures and the very low cost of the ultimate starting materials (both the acetylene and benzyl chloride are only cents/g) means that the route of Scheme $4{ }^{24}$ is rather attractive for the synthesis, at gram and above scales, of electron-rich tetracenes (2).

Preparation of the parent tetracene $(2, \mathrm{~T})$ itself can be attained in higher efficiency by using the approaches in Scheme 5 (cf. Route II Scheme 3). The reaction of 1,2-bis(halogen-methyl)benzene $\mathbf{8}(\mathrm{X}=\mathrm{Cl}$ is commercially available; $\mathrm{X}=\mathrm{Br}$ is easily prepared by bromination of $o$-xylene) and $\mathbf{9}$ provides intermediate $\mathbf{1 0}$ in good yield via a published procedure. ${ }^{25}$ In our hands, the synthesis of $\mathbf{1 0}$ has been further developed for both unsubstituted and substituted variants of $\mathbf{8}$ and $9 .{ }^{26}$ Alternatively, compounds of type $\mathbf{1 0}$ can be 


\section{Short review for Synthesis}

synthesised (both unsubstituted and substituted) through reaction of phthalaldehyde $\mathbf{9}$ and dihydroxy naphthalene $\mathbf{1 0}$ applying published procedure. ${ }^{27} \mathrm{~A}$ practical reduction of $\mathbf{1 0}$ to give tetracene could be performed with aluminium alkoxides (using commercial $\mathrm{Al}(\mathrm{O}-s-\mathrm{Bu})_{3}$ to provide good yields). The materials costs for the synthesis of tetracene on a $10 \mathrm{~g}$ scale starting from 1,2-bis(chloromethyl)benzene(8a) route is ca. $1 € / \mathrm{mmol}$ and from phthalaldehyde $\mathbf{1 1} 2.50 € / \mathrm{mmol}$; this is at least $10 \times$ less than typical commercial retail cost of the parent $\mathrm{T}(\mathbf{2})$.

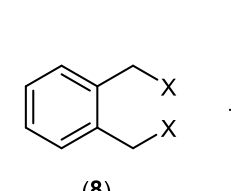

(8) $\mathrm{X}=\mathrm{Cl}$ a $\mathrm{X}=\mathrm{Br} \mathbf{b}$<smiles>O=Cc1ccccc1C=O</smiles>

(11)<smiles>O=C1C=CC(=O)c2ccccc21</smiles>

(9)<smiles>O=C1c2ccccc2C(=O)c2cc3ccccc3cc21</smiles>

(10)

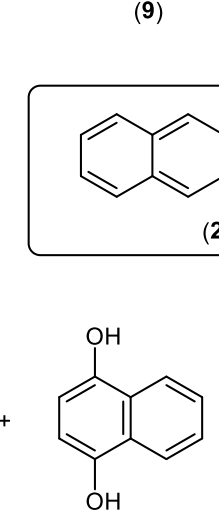

(12)<smiles>O=C1c2ccccc2C(=O)c2cc3ccccc3cc21</smiles>

(10)

Scheme 5. Practical unidirectional synthesis approaches for synthesis of tetracene $(2, \mathrm{~T})$.

The "furan/benzyne" approach (Routes IV-V of Scheme 3) has been presented in two literature variants, ${ }^{28}$ both of which are practical and viable approaches, although multistep synthesis is necessary in this case. In one case the readily available acetal $\mathbf{1 3}$ is converted into the bis-silylfuran intermediate $\mathbf{1 4}$ and reacted with in situ generated benzyne 15 providing reactive 16 in good yield (Scheme 6). Derivative $\mathbf{1 6}$ reacts rapidly and almost quantitatively with TFA to form $5(12 H)$ naphthacenone $\mathbf{1 7}$, which leads after reduction/dehydratation to tetracene $(2, \mathrm{~T}){ }^{28 a}$

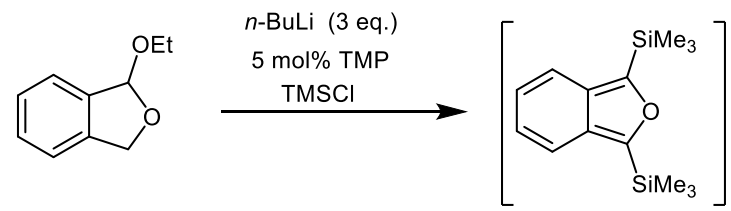

(13)

(14)

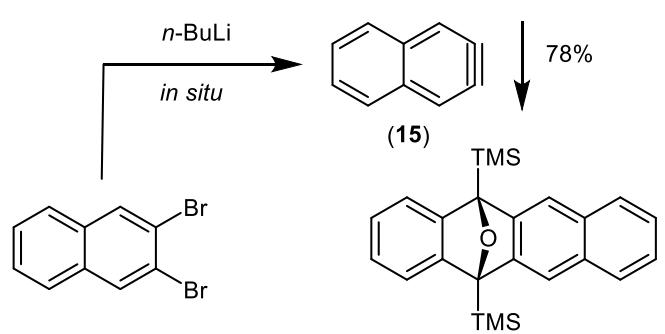<smiles>c1ccc2cc3cc4ccccc4cc3cc2c1</smiles>

(2) $\mathrm{T}$
(16)

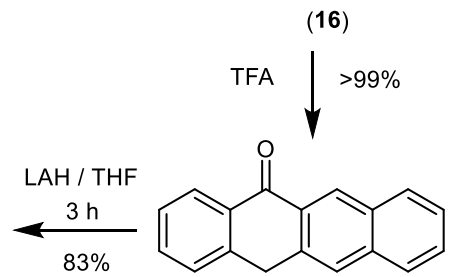

(17) 
Scheme 6. Synthesis of tetracene $(2, T)$ applying the "furan/benzyne" approach of route IV. ${ }^{28 a}$

A second variant of the "furan/benzyne" approach ${ }^{28 \mathrm{~b}}$ refers to the two bidirectional approach of Route V, in which benzyne formation is performed in situ from $\mathbf{1 8}$ and allowed to react with the furan 19, leading to the di-epoxy-tetrahydronaphthacene $\mathbf{2 0}$ in moderate yields. The catalytic hydrogenation of the unsubstituted 20a to 21a is high yielding and the subsequent dehydratation (TFA/CHCl 3 or $\mathrm{HCl} / \mathrm{MeOH}$ ) provides easily the tetracene (2). The tetramethyl substituted compound $\mathbf{2 1 b}$ possesses extreme acid lability and is thus directly converted with aqueous $\mathrm{HCl}$ into the tetramethyltetracene (22).<smiles>COc1cc2cc(O)c(Br)cc2cc1Br</smiles>

(18)

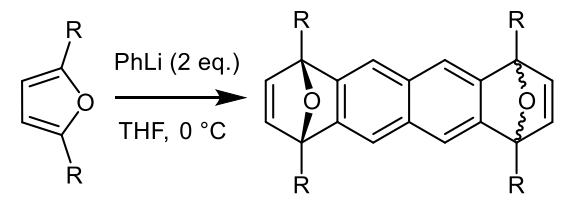

(20) a $\mathrm{R}=\mathrm{H} \quad 40 \%$ b $\mathrm{R}=\mathrm{Me} 44 \%$ $10 \%$
$\mathrm{Pd} / \mathrm{C}$ $\mathrm{Pd} / \mathrm{C}$

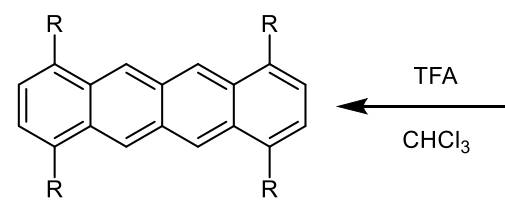

(2) $\mathrm{T} \quad \mathrm{R}=\mathrm{H} \quad 78 \%$ (22) $\mathrm{R}=\mathrm{Me} 56 \%$<smiles></smiles>

(21) a $\mathrm{R}=\mathrm{H} \quad 80 \%$ b $\mathrm{R}=\mathrm{Me}($ not isolated $)$

Scheme 7. Synthesis of tetracene (2, T) and its 1,4,7,10-tetramethyl analogue applying the "furan/benzyne" approach of route $V^{28 b}$

A final feasible, but less common, strategy in tetracene formation is the cycloaddition of benzocyclobutane $\mathbf{2 3}$ to epoxides $\mathbf{2 4}$ (Route VI), providing the intermediates 25 in good yields (Scheme 8) ${ }^{29}$ The further conversion to compounds $\mathbf{2 6}$ and the subsequent aromatisation provides tetracene (2) and dibromotetracene (27) in excellent yields. ${ }^{29}$ One advantage of such approaches is that dihydroacenes, ${ }^{23 c}$ such as $\mathbf{2 6}$ are frequently significantly more soluble than their aromatic analogues which obviously facilitates their purification by chromatography. In balance to this, an additional (slow, high catalyst loading) step is required at the end of the sequence for aromatisation and any functional groups present must also be tolerant of the $\mathrm{Pd} / \mathrm{C}$. 


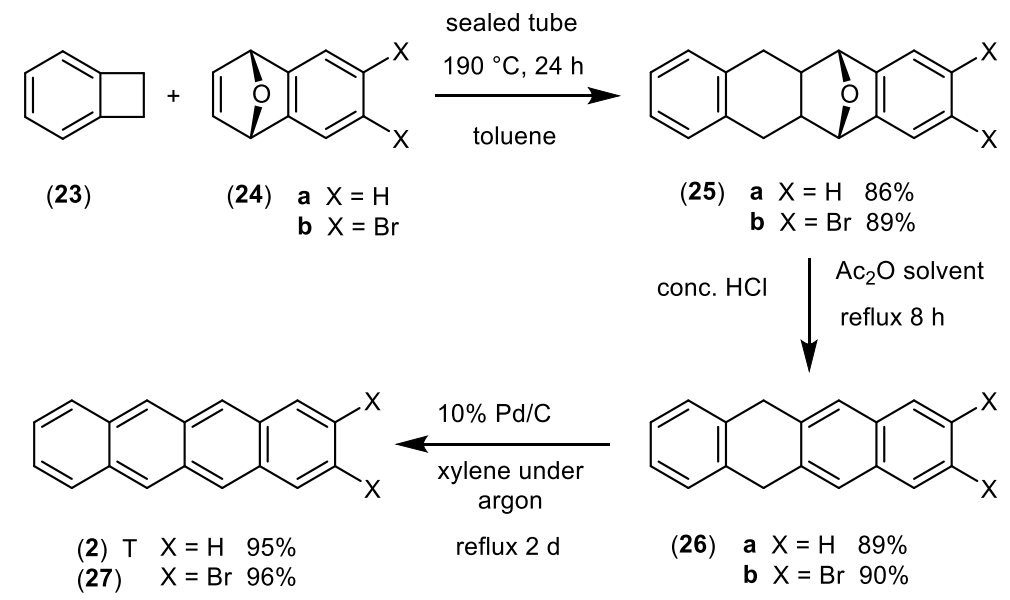

Scheme 8. Synthesis of tetracene applying the "electrocylic opening" approach (Route VI). ${ }^{29}$

In summary, based on their frequency of use and ease of implementation, Routes I-VI (Scheme 3) as exemplified above, presently to offer the most attractive approaches for the preparation of tetracene $(2, \mathrm{~T})$ and its substituted derivatives allowing access to TTT derivatives at multi-gram scales and substituted TTTs in research amounts suitable for device preparation. The latter is considered in the next section.

\section{Materials and device applications}

Typically TE device preparation requires a p/n conductor junction that spans the temperature gradient so that the charge carriers $\left(\mathrm{e}^{-}\right.$and $\left.\mathrm{h}^{+}\right)$both flow down the 'legs' towards the cold surface (Figure 4a). When screening for improved materials one of the $\mathrm{n}$ or p-type legs is typically of known performance so that the characteristics of the new TE species is extracted more easily. The majority of organic devices prepared so far have used the p-type co-polymer PDOT-PSS, which is attractive as thin-films of this material are easily cast. The poor solubility of TTT material makes vacuum deposition of thin-films more attractive as gasphase doping also allows preparation of both the $\mathrm{n}$ and $\mathrm{p}$-legs (Figure $4 \mathrm{~b}$ ) into a functioning in-plane generator (Figure $4 \mathrm{c}$ ). ${ }^{30}$

(a)

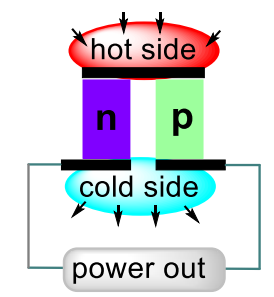

(c)

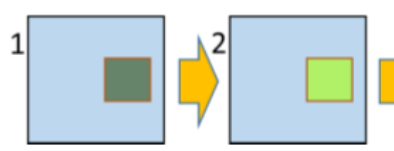

(b)
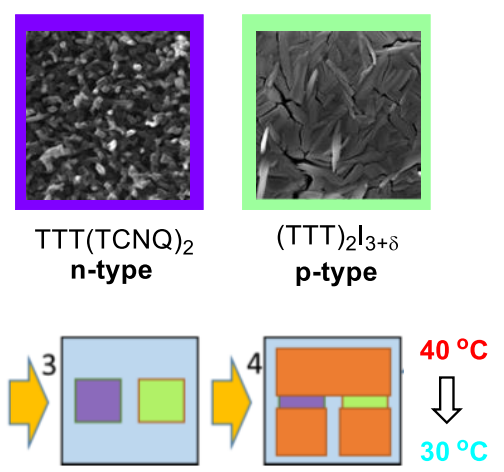

Figure 4. (a) Typical TE device architecture. (b) Electron micrographs (ca. $8 \times 8 \mu \mathrm{m}$ areas) of crystalline films of TTT(TCNQ) $)_{2}$ and (TTT) $)_{2} \mathrm{I}_{3+\delta}$. (c) Stepwise construction of the OTE device: 1 . TTT deposited; 2. TTT doped with iodine to (TTT) $)_{2} \mathrm{I}_{3+\delta} ; 3$. TTT(TCNQ) $)_{2}$ placed by reactive co-deposition of TTT and TCNQ; 4. $\mathrm{n} / \mathrm{p}$ junction completed by over deposition of copper electrodes. Each of the small squares in the images 14 are ca. $1 \mathrm{~cm}^{2}$ (reproduced in part with permission from Adv. Electron. Matter. ref. 30).

Only very small amounts of power $(50 \mathrm{pW}$ at $1 \mathrm{mV})$ are attained by the device in Figure 4. Greater amounts of power in such thin-film configurations would be attained by use of multiple junctions in series or increasing the thickness and length of the $\mathrm{p} / \mathrm{n}$ legs. One alternative method to increase TE device 


\section{Short review for Synthesis}

performance for TTT systems is through use of single crystal devices as formally no crystal grain boundaries exist leading to greatly improved carrier mobility. This approach has been partially realised by Huewe, Steeger and Pflaum who have successfully developed apparatus (Figure 5) for the simultaneous measurement of $\sigma, \alpha$ and $\kappa$ on single crystals of (TTT) $)_{2} \mathrm{I}_{3+\delta .}{ }^{22}$ The electrical conductivity of these single crystals $\left(2.1 \times 10^{3}\right.$ $\mathrm{S} \mathrm{cm}^{-1}$ at room temperature) is ideal for an organic TE and the $\alpha$ values are acceptable $\left(+42 \mu \mathrm{V} \mathrm{K}^{-1}\right)$. Unfortunately, the crystal's thermal conductivity was much higher than anticipated $\kappa=(3.7 \pm 0.2) \mathrm{W}(\mathrm{m}$ $\mathrm{K})^{-1}$ ] leading to a poor $\mathrm{ZT}_{\mathrm{RT}}=0.03$ value. Nevertheless, single crystals of $(\mathrm{TTT})_{2} \mathrm{I}_{3+\delta}$ combined with the $\mathrm{n}-$ type material $\mathrm{Cu}(\mathrm{DNDQI})_{2}$ provide a device generating $\sim 20 \mathrm{nW}$ from only a $30^{\circ} \mathrm{C}$ temperature difference. This power is being driven off of a total crystal cross-sectional area of only ca. $10^{-8} \mathrm{~m}^{2}$. If many such crystals could be bundled into a $1 \mathrm{~cm}^{2}$ array enough power could theoretically drive small personalised electronics ( $\sim 1 \mathrm{~mW}$, about a thousand times higher than current PDOT-PSS based devices).

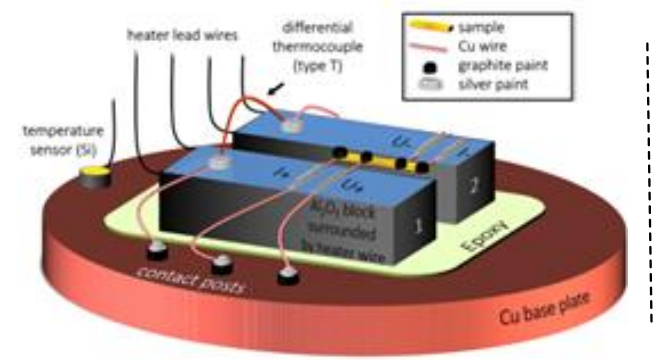<smiles>CC1=CC(=NC#N)C(C)=CC1=NC#N</smiles>

Figure 5. The Huewe-Steeger-Pflaum apparatus for simultaneous measurement of all thermoelectric parameters and the structure of 2,5-dimethyl- $N, N$-dicyanoquinodiimine (DNDQI) (reproduced with permission from Adv. Matter. ref. 22).

\section{6. $\quad$ Future perspective (100-220 words, currently 313)}

Although the results of Section 5 demonstrate proof-of-concept in the use of thio-substituted tetracenes, especially TTT a great deal of optimisation will be required to develop materials and devices of practical utility. In particular improvement of $\sigma$ and $\alpha$, ideally with reduction of the thermal parameter $\kappa$ needs to be achieved. There are indications that this is possible as the tetracenes of Scheme 9 (see also Section 4) are converted into substituted TTTs. ${ }^{24}$ Known derivatives 1b-e provide films with Seebeck coefficients of similar level to the parent TTT on doping with iodine $\left(\alpha=17-25 \mu \mathrm{V} \mathrm{K}^{-1}\right)$. However, the new 2,8disubstituted derivatives 1f-j show significantly increased $\alpha$ values (Scheme 9). Recent analyses showing strong correlation between $\alpha$ and $\sigma$ and indications that crystalline conductors behave significantly differently to their polymer analogues. ${ }^{31}$ This together with the possibilities to use TTT cores in both $\mathrm{p}$ and $\mathrm{n}$ type conductors means that significant potential exists for development for these materials in both TE and other applications.

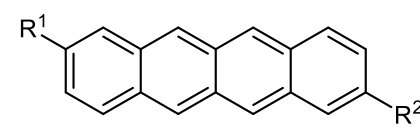

(2)

$$
\begin{array}{c|c}
\mathrm{S}_{8} \mathrm{DMF} \\
155^{\circ} \mathrm{C} \downarrow
\end{array}
$$

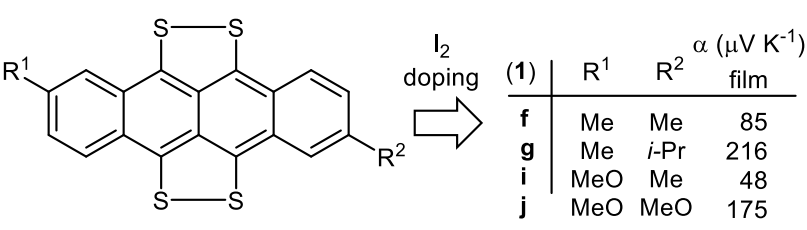

\begin{tabular}{ccc} 
(2) & $\mathrm{R}^{1}$ & $\mathrm{R}^{2}$ \\
\hline $\mathbf{b}$ & $\mathrm{H}$ & $\mathrm{Me}$ \\
$\mathbf{c}$ & $\mathrm{H}$ & $\mathrm{MeO}$ \\
$\mathbf{e}$ & $\mathrm{H}$ & $\mathrm{Ph}$ \\
$\mathbf{f}$ & $\mathrm{Me}$ & $\mathrm{Me}$ \\
$\mathbf{g}$ & $\mathrm{Me}$ & $i-\mathrm{Pr}$ \\
$\mathbf{i}$ & $\mathrm{MeO}$ & $\mathrm{Me}$ \\
$\mathbf{j}$ & $\mathrm{MeO}$ & $\mathrm{MeO}$
\end{tabular}

$\mathrm{MeO} \mathrm{MeO} 175$

(1)

Scheme 9. 2,8-disubstituted TTTs with improved Seebeck coefficients on $I_{2}$ doping. ${ }^{24}$ 
Further very useful approaches to obtain substituted tetracenes (2) can also be envisaged and these are summarised in Scheme 10. Especially promising are the organocatalytic approaches for construction of tetracene-precursors that have been recently published (Scheme 10). ${ }^{32}$

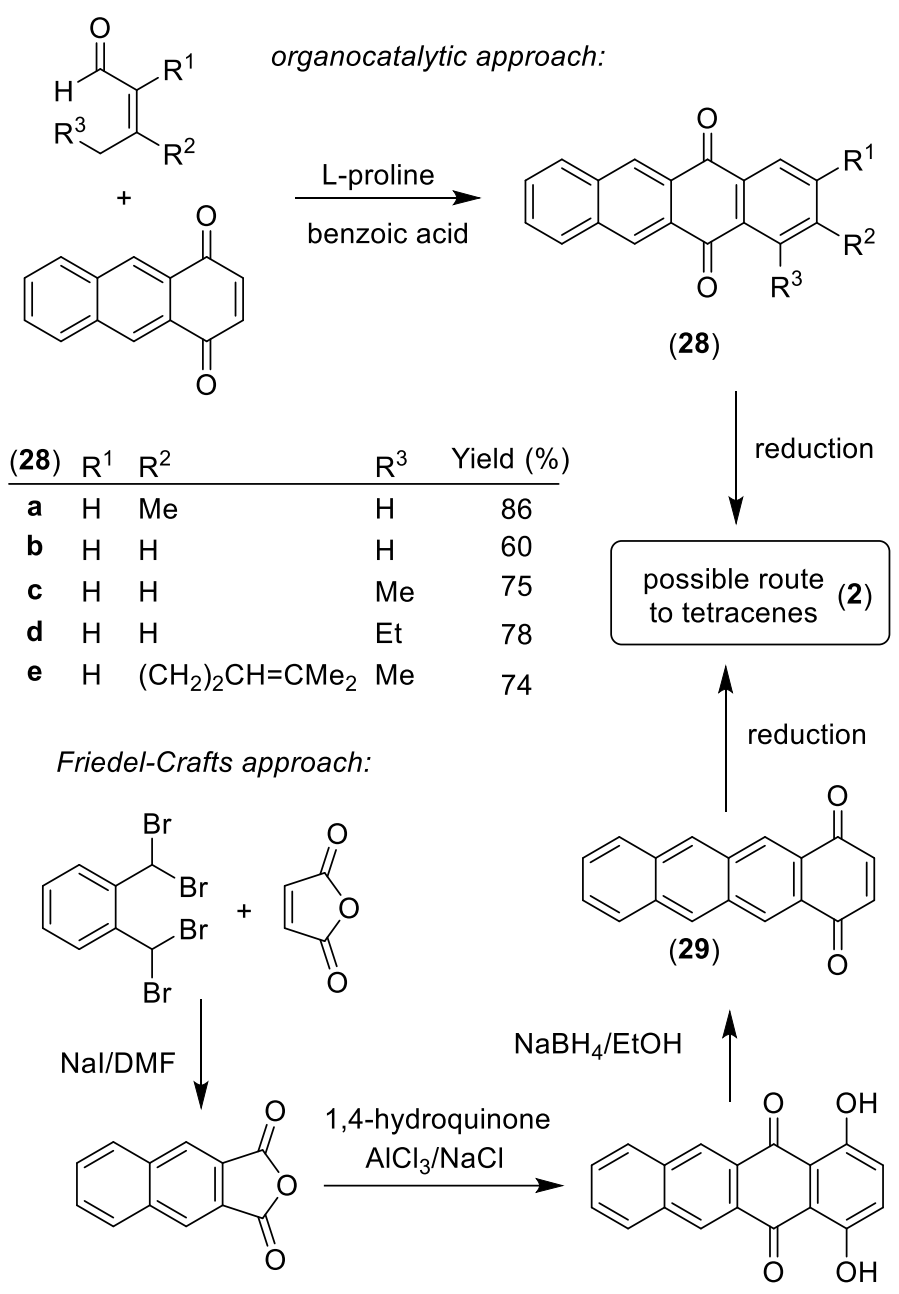

Scheme 10. Promising synthetic approaches for further development offering opportunities for diverse substituted tetracenes (2).

Tetracenediones (28) are thus synthesised in one step in yields in the range 60-86\%. The development of suitable reduction procedure seems very feasible and would provide tetracenes in just two steps. As an alternative Friedel-Crafts approach by using naphthalic anhydride and the subsequent reduction to the 1,4tetracenequinone (29) is high yielding ${ }^{33}$ and may find further development to an efficient procedure for tetracenes (2), or indeed pentacenes, and their sulfur derivatives. Such ideas clearly indicate the significant opportunities that exist for the involvement of main stream organic chemists in the development of new thermoelectric materials. New exemplars of sustainable chemistry and future exciting and exceptional materials should be expected.

\section{References}

(1) For a primer in 'inorganic-based' development of TE materials see: (a) Goldsmid, H. J. Introduction to Thermoelectricity; Springer: Berlin, 2010. Impressively, in 1954 Julien Goldsmid could already 
show TE/Peltier cooling below $0{ }^{\circ} \mathrm{C}$ using $\mathrm{Bi}_{2} \mathrm{Te}_{3}$; the same year that the first poorly electrically conducting organic charge-transfer complexes had only just appeared, see: Akamatsu, H.; Inokuchi, H.; Matsunaga Y. Nature 1954, 173, 168.

(2) The most recent (2014) exceptional inorganic material is SnSe, showing ZT up to 2.6 (but at $650{ }^{\circ} \mathrm{C}$ ), see: Zhao, L. D.; Lo, S. H.; Zhang, Y. S.; Sun, H.; Tan, G. J.; Uher, C.; Wolverton, C.; Dravid, V. P.; Kanatzidis, M. G. Nature 2014, 508, 373 and citations thereof.

(3) Thus far, developments in the organic area have been dominated by polymer systems, especially, poly(3,4-ethylenedioxythiophene) (PEDOT). For an excellent introduction to the area of organic (polymer) TEs see: Taroni, P. J.; Hoces, I.; Stingelin, N.; Heeney, M.; Bilotti, E. Isrl. J. Chem. 2014, 54, 534 references therein and citations thereof.

(4) Parker, T.; Marder, S. Synthetic Methods in Organic Electronic and Photonic Materials: A Practical Guide; Royal Society of Chemistry, Cambridge, 2015.

(5) Kroon, R.; Mengistie, D. A.; Kiefer, D.; Hynynen, J.; Ryan, J. D.; Yu, L.; Müller, C. Chem. Soc. Rev. 2016, 45, 6147 and references therein.

(6) (a) Harada, K.; Sumino, M.; Adachi, C.; Tanaka, S.; Miyazaki, K. App. Phys. Lett. 2010, 96, 253304. Higher Seebeck values (ca. 250-500 $\mu \mathrm{V} \mathrm{K}^{-1}$ ) have been reported but at minimal current, see (c) von Mühlenen, A.; Errien, N.; Schaer, M.; Bussac, M.-N.; Zuppiroli, L. Phys. Rev. B 2007, 75, 115338.

(7) (a) Cho, C.; Wallace, K. L.; Tzeng, P.; Hsu, J.-H.; Yu, C.; Grunlan, J. C. Adv. Energy Mater. 2016, 6, 1502168. (b) Blackburn, J. L; Ferguson, A. F.; Cho, C.; Grunlan, J. C. Adv. Mater. 2018, 30, 1704386 and references therein.

(8) Sun, Y.; Qiu, L.; Tang, L.; Geng, H.; Wang, H.; Zhang, F.; Huang, D.; Xu, W.; Yue, P.; Guan, Y.; Jiao, F.; Sun, Y.; Tang, D.; Di, C.; Yi, Y.; Zhu D. Adv. Mater. 2016, 28, 3351.

(9) Shi, K.; Zhang, F.; Di, C.-A.; Yan, T.-W.; Zou, Y.; Zhou, X.; Zhu, D.; Wang, J.-Y.; Pei, J. J. Am. Chem. Soc. 2015, 137, 6979.

(10) In p-type materials (a) Russ, B.; Glaudell, A.; Urban, J. L.; Chabinyc, M. L.; Segalman, R. L. Nature Rev. Mater. 2016, 1, 16050. Recently a similar trend was found in organic n-type materials (b) Zuo, G.; Li, Z.; Wang, E.; Kemerink, M. Adv. Electron. Mater. 2018, 4, 1700501.

(11) For a historical summary of organic superconductors see: D. Jérome, D. In The Physics of Organic Superconductors and Conductors, Springer Series in Materials Science, Vol. 110, Lebed, A. Ed.; Springer: Berlin, 2008, 3.

(12) Overviews of TTT materials: (a) Otsubo, T.; Takimiya, K. Rev. Heteroatom Chem. 1997, 16, 69. (b) T. Otsubo, T.; Takimiya K.; Aso, Y. Phosphorus, Sulfur Silicon Relat. Elem. 1998, 136, 447. (c) Otsubo, T. Synlett 1997, 544. (d) Bendikov, M.; Wudl, F.; Perepichka, D. F. Chem. Rev. 2004, 104, 4891. (e) Zhang, L.; Fakhouri, S. M.; Liu, F.; Timmons, J. C.; Ram, N. A.; Briseno, A. L. J. Mater. Chem. 2011, 21, 1329.

(13) (a) Schegolev, I. F.; Yagubskii, E. B. In Extended Linear Chain Compounds, Vol. 2; Miller, J. S., Ed.; Plenum Press: New York, 1982, 385. (b) Shibaeva, R. P. In Extended Linear Chain Compounds, Vol. 2; Miller, J. S., Ed.; Plenum Press: New York, 1982, 435.

(14) Peierls was the first to predict that a perfectly space 1D lattice would distort to favour pairwise interactions over longer range band structures leading to insulating over conducting behaviour. For a more formal introduction see chapter 4 in: Roth, S.; Carrol, D. In One Dimensional Metals, $3^{\text {rd }}$ Ed.; Wiley-VCH: Weinheim, 2015.

(15) Quasicrystals are ordered structures that additionally show non periodic behaviour. They were discovered by Dan Shechtman (Nobel laureate 2011). For an introductory text see: Janot, C. In Quasicrystals: A Primer, $2^{\text {nd }}$ Ed.; Oxford University Press, 2012.

(16) Dresselhaus, M. S.; Chen, G.; Tang, M. Y.; Yang, R. G.; Lee, H.; Wang, D. Z.; Ren, Z. F.; Fleurial, J.P.; Gogna P. Adv. Mater. 2007, 19, 1043.

(17) Casian, A.; Dusciac, V.; Coropceanu, I. Phys. Rev. B 2002, 66, 165404.

(18) Casian, A. Phys. Rev. B 2010, 81, 155415, 2010.

(19) (a) Perez-Alberne, E. A. U.S. Patent 3723417 A 19730327, 1973, pp. 4 [Chem. Abs., 1973, 78, 159696]. (b) Marschalk, C.; Stumm, C. Bull. Soc. Chim. Fr. 1948, 418 [Chem. Abs. 1950, 44, 49302]. (c) Balodis, K. Tezisy Dokl. Konf. Molodykh Uch. 1978, 26-27 (conference proceedings in Russian) [Chem. Abs. 1980, 92, 215353]. (d) Medne, R.; Kraupsa, I.; Neilands, O. Kimijas Serija 1989, 633. 
Short review for Synthesis

[Chem. Abs. 1990, 112, 178743]. (e) Alder, A. Eur. Pat. Appl. EP 511164 A1 19921028, 1992, 5 pp. [Chem. Abs. 1993, 118, 101960].

(20) Garrett, M. R.; Durán-Peña, M. J.; Lewis, W.; Pudzs, K.; Uzulis, J.; Mihailovs, I.; Tyril, B.; Shine, J.; Smith, M. F.; Rutkis, M.; Woodward, S. J. Mater. Chem. C 2018, 6, 3403.

(21) (a) Yagodkin, E.; Xia, Y.; Kalihari, V.; Frisbie, C. D.; Douglas, C. J. J. Phys. Chem. C 2009, 113, 16544. (b) Yagodkin, E.; McGarry, K. A.; Douglas, C. J. Org. Prep. Proced. Int. 2011, 43, 360-363.

(22) Huewe, F.; Steeger, A.; Kostova, K.; Burroughs, L.; Bauer, I.; Strohriegl, P.; Dimitrov, V.; Woodward, S.; Pflaum, J. Adv. Mater., 2017, 29, 1605682.

(23) (a) Qu, H.; Chi, C. Curr. Org. Chem. 2010, 14, 2070. (b) Watanabe, M.; Chen, K.-Y.; Chang, Y. J.; Chow, T. J. Acc. Chem. Res. 2013, 46, 1606. (c) Dorel, R.; Echavarren, A. M. Eur. J. Org. Chem. 2017, 14.

(24) Woodward, S.; Ackermann, M.; Ahirwar, S.; Burroughs, L.; Garrett, M. R.; Ritchie, J.; Shine, J.; Tyril, B.; Simpson, K.; Woodward, P. Chem. Eur. J. 2017, 23, 7819 and references therein.

(25) Kaur, I.; Jazdzyk, M.; Stein, N. N.; Prusevich, P.; Miller, G. P. J. Am. Chem. Soc. 2010, 132, 1261.

(26) Dimitrov, V. manuscript in preparation.

(27) Reichwagen, J.; Hopf, H.; Del Guerzo, A.; Belin, C.; Bouas-Laurent, H.; Desvergne, J.-P. Org. Lett. 2005, 7, 971.

(28) (a) Netka, J.; Crump, S. L.; Rickborn, B. J. Org. Chem. 1986, 51, 1189. (b) Gribble, G. W.; Perni, R. B. J. Org. Chem. 1985, 50, 2934.

(29) Luo, J.; Hart, H. J. Org. Chem. 1987, 52, 4833.

(30) Pudzs, K.; Vembris, A.; Rutkis, M.; Woodward, S. Adv. Electron. Mater. 2017, 3, 1600429.

(31) Kang, S. D.; Snyder, G. J. Nature Mat. 2017, 16, 252.

(32) Magar, K. B. S.; Xia, L.; Lee, Y. R. Chem. Commun. 2015, 51, 8592.

(33) PatneyH. K. J. Org. Chem. 1988, 53, 6106.

\section{For author summary}

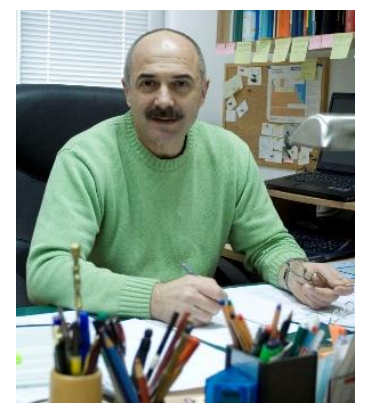

Vladimir Dimitrov was born in 1953 in Sofia (Bulgaria). After a diploma in synthetic organic chemistry (1977) and $\mathrm{PhD}(1981)$ at the Technical University Leuna-Merseburg (Germany, now Martin-Luther University Halle-Wittenberg) started his Independent research at the Institute of Organic Chemistry with Centre of Phytochemistry of the Bulgarian Academy of Sciences in 1985 where he has stayed rising to being professor and head of department. In 1989-90 he was also an Alexander von Humboldt Fellow at the Max Planck Institute at Mulheim (Germany) and in 1999-2001 Senior research fellow at the Institute of Organic Chemistry, University of Zurich (Switzerland). His diverse research interests include: stereoselective C-C-bond forming reactions, chiral catalysis and the synthesis of multifunctional organic compounds. 


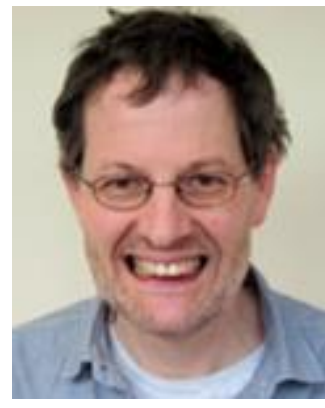

Simon Woodward received both his B.Sc. and Ph.D. in chemistry at the University of Sheffield (UK) in between 1982-1987. Between 1988-1989 he undertook periods of postdoctoral work with Prof. M. David Curtis (as a Fullbright Fellow) and Dr. John M. Brown, FRS at the Universities of Michigan (USA) and Oxford (UK). In 1990 he was first appointed to as a lecturer at the University of Hull (UK) and subsequently (1999) moved to the University of Nottingham where he presently holds a chair in synthetic organic chemistry. His research interests include organometallic and catalytic chemistry and their application to the preparation of molecules of high utility including organic electronic (thermoelectric) materials.

\section{Table of Contents Entry}

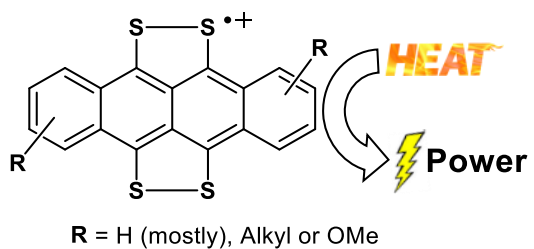

Preparation of new and existing tetrathiotetracene (TTT) derivatives offers new opportunities for direct heat to power conversion via the thermoelectric effect. 